\title{
Levantamento florístico das comunidades de macroalgas da bacia do Rio das Pedras, região centro-sul do Estado do Paraná, Sul do Brasil
}

\author{
Rogério Antonio Krupek ${ }^{1}$, Ciro Cesar Zanini Branco ${ }^{1,2}$ e Cleto Kaveski Peres ${ }^{1}$
}

Recebido: 03.07.2007; aceito: 30.05.2008

\begin{abstract}
Floristic survey of macroalgal of the Pedras River Basin, mid-southern region of Paraná State, Southern

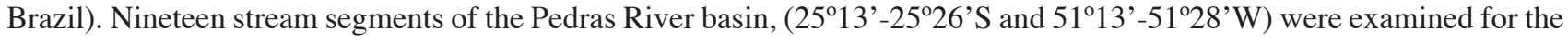
presence of macroalgae, of which 16 were visited once during the period of July 26 to August 212004 and three monthly from April 2004 to May 2005. Twenty nine infrageneric taxa and five "vegetative groups" were found. Cyanobacteria and Chlorophyta were the best represented divisions, followed by Rhodophyta and Heterokontophyta. Despite predominance of blue-green and green algae has been previously reported in several studies, the macroalgal flora of the Pedras River Basin showed, in general way, significant differences to other Brazilian regions. These results suggest that macroalgal communities are still little known, reflecting, basically, the scarcity of studies focusing these important primary producers in lotic ecosystem from Southern Brazil, particularly in Paraná State.
\end{abstract}

Key words: biodiversity, macroalgae, stream, Paraná state

RESUMO - (Levantamento florístico das macroalgas da bacia do rio das Pedras, região centro-sul do Estado do Paraná, Sul do Brasil). Dezenove segmentos de riachos da Bacia do Rio das Pedras (25 $13^{\circ}-25^{\circ} 26^{\prime} \mathrm{S}$ e $\left.51^{\circ} 13^{\prime}-51^{\circ} 28^{\prime} \mathrm{W}\right)$ foram examinados quanto à presença de macroalgas, dos quais 16 foram visitados uma vez durante o período de 26 de julho a 21 de agosto de 2004 e três mensalmente de abril de 2004 a maio de 2005 . Vinte e nove táxons infragenéricos e cinco grupos vegetativos foram encontrados. Cyanobacteria e Chlorophyta foram as divisões melhores representadas, seguidas de Rhodophyta e Heterokontophyta. Embora o predomínio de algas azuis e verdes ter sido previamente reportado em vários estudos, a flora da Bacia do Rio das Pedras apresentou, de modo geral, diferenças significativas em relação ao reportado para outras regiões brasileiras. Estes resultados sugerem que tais comunidades são relativamente pouco conhecidas, refletindo a escassez de estudos envolvendo estes importantes produtores primários em ambientes lóticos da região Sul do Brasil, particularmente no Estado do Paraná.

Palavras-chave: biodiversidade, macroalgas, riachos, Estado do Paraná

\section{Introdução}

Estudos que apresentam como enfoque principal aspectos taxonômicos de comunidades de macroalgas de ambientes lóticos são relativamente escassos, entretanto, diversos trabalhos que incluem algum tipo de informação taxonômica foram desenvolvidos em várias regiões do mundo (Sheath et al. 1986, Entwisle 1989, Whitton et al. 1991, Sheath \& Cole 1992, Filkin et al. 2003). Especificamente no Brasil, estudos desta natureza são igualmente ou ainda mais escassos, sendo quase exclusivamente restritos ao Estado de São Paulo (Necchi Júnior et al. 1995, 1997, Branco \& Necchi Júnior 1996), onde diversos biomas foram estudados quanto à composição florística das comunidades de macroalgas de rios e riachos. Neste contexto, Branco \& Necchi Júnior (1996) realizaram um estudo na região oriental da Mata Atlântica e Necchi Júnior et al. (1997) na região Noroeste. Foram, ainda, estudadas regiões de Cerrado, Águas Duras e Floresta Tropical (Necchi Júnior et al. 2000). Há estudos enfocando este grupo de algas em ambientes lóticos de outras regiões (e.g. Necchi Júnior et al. 2003), sendo praticamente inexistentes no Estado do Paraná.

Os únicos trabalhos publicados até o presente momento sobre as comunidades de macroalgas de riachos do Estado do Paraná são os de Peres et al. (2008), realizado na área da Serra da Prata, região leste, e Branco et al. (2008), conduzido nos limites da

1. Universidade Estadual Paulista, Faculdade de Ciências e Letras, Departamento de Biologia, Av. Dom Antônio 2100, 19806-900 Assis, SP, Brasil

2. Autor para correspondência: czbranco@assis.unesp.br 
Floresta Nacional de Irati, região centro-sul. Em ambos os estudos os autores sugerem que a composição das comunidades investigadas variou bastante em relação aos estudos previamente realizados em outras regiões geográficas e/ou biomas do país. Concluíram, assim, que as comunidades de macroalgas lóticas do Paraná são ainda pouco conhecidas e, por isso, recomendaram fortemente a realização de mais estudos a fim de melhor compreender a biodiversidade e a biogeografia destas comunidades algais no Estado.

Considerando, assim, a carência de informações para o Estado do Paraná, o objetivo deste estudo foi realizar o levantamento taxonômico das comunidades de macroalgas da Bacia do Rio das Pedras, localizada na região centro-sul do Estado do Paraná, Sul do Brasil.

\section{Material e métodos}

A bacia hidrográfica do Rio das Pedras (figura 1) desenvolve-se no reverso da escarpa basáltica denominada Serra da Esperança, sendo esculpida na unidade toleítica inferior da Formação Serra Geral, definida por rochas de natureza básica-intermediária (terceiro planalto paranaense) (Maack 2002). Com uma área de $330 \mathrm{~km}^{2}$ está localizada no município de Guarapuava, Estado do Paraná, entre as latitudes $25^{\circ} 13^{\prime} 10^{\prime \prime} \mathrm{S}$ e $25^{\circ} 26^{\prime} 24^{\prime \prime} \mathrm{S}$ e as longitudes $51^{\circ} 13^{\prime} 10^{\prime \prime} \mathrm{W}$ e $51^{\circ} 28^{\prime} 40^{\prime \prime} \mathrm{W}$. Apresenta-se constituída basicamente pela Floresta Ombrófila Mista, mais especificamente a alto Montana (Maack 2002). A cobertura vegetal recobre cerca de $65 \%$ da área total da bacia. As áreas de matas são caracterizadas por formações arbóreas, principalmente mata primária e secundária em estágio de regeneração e as capoeiras, formações arbustivas, geralmente compostas por espécies pioneiras (Battistelli et al. 2004).

Dezenove segmentos de riachos foram examinados para a presença/ausência de macroalgas. Destes, 16 foram visitados uma única vez durante o período de 26 de julho a 21 de agosto de 2004, e três (pontos 17,18 e 19) foram visitados mensalmente durante o período de abril de 2004 a março de 2005. As observações foram feitas dentro de uma transecção de 10 metros de extensão (Necchi Júnior et al. 1995) subdividida em partes iguais de 1 metro, ao longo de cada margem de cada rio/riacho estudado, as quais tiveram o leito completamente examinado para presença de macroalgas.

Foi adotado o conceito de macroalga definido por Sheath \& Cole (1992): "Tipicamente, macroalgas de riachos são bentônicas e formam um talo maduro que é uma estrutura discreta e reconhecível a olho nu; a identificação microscópica é geralmente necessária e, freqüentemente, microalgas estão associadas ao talo". A coleta e preservação das amostras de algas utilizadas seguiram os procedimentos descritos por Necchi Júnior et al. (1991). O exame microscópico foi feito com microscópio binocular Carl Zeiss - Jenamed 2. As medidas microscópicas foram realizadas com o auxilio de ocular micrometrada acoplada ao microscópio. Dez medidas foram tomadas ao acaso, com base na fórmula $n=(\mathrm{s} / \mathrm{E} \overline{\mathrm{X}})^{2}$ (Southwood 1978), onde $\mathrm{s}=$ desvio padrão, $\overline{\mathrm{x}}=$ média e $\mathrm{E}=$ erro padrão pré-determinado (neste caso 0,05). Para as análises morfométricas e ilustrações (fotomicrografias) foi utilizado um sistema de câmera de vídeo digital Leica, modelo DFC-280, acoplado a um microcomputador com o software Leica IM-50, específico para análise de imagem. A classificação das espécies em divisões seguiu o sistema de Van de Hoek et al. (1995), exceto para Cyanobacteria (Komárek \& Anagnostidis 1986, 1989, Anagnostidis \& Komárek 1988, 1990) e Charophyceae (Lee 1989).

Para todos os táxons inventariados há uma breve descrição e ilustrações (fotomicrografias) baseadas no material analisado. As medidas de diâmetro (diâm.) e comprimento (compr.) das células vegetativas e/ou reprodutivas são apresentadas para todos os táxons, ao passo que a relação comprimento/ diâmetro celular (compr./diâm.) foi apresentada, em particular, para as Cyanobacteria. Comentários taxonômicos, quando necessários, incluem aspectos da caracterização e/ou dificuldades na identificação e discrepâncias em comparação com a literatura. São apresentados, ainda, os pontos de amostragem onde ocorreram na Bacia do Rio das Pedras e as características físicas e químicas dos riachos onde ocorreram. Espécimes representativos de todo o material analisado foram incorporados ao Herbário SJRP(Holmgren \& Holmgren 1993).

\section{Resultados}

\section{CYANOBACTERIA}

Chroococcopsis fluviatilis (Langherheim) Komárek \& Anagnostidis, Preslia 67:17. 1995 =Pleurocapsa fluviatilis Lagerheim, Notarisia 3: 430. 1888.

Figura 2 


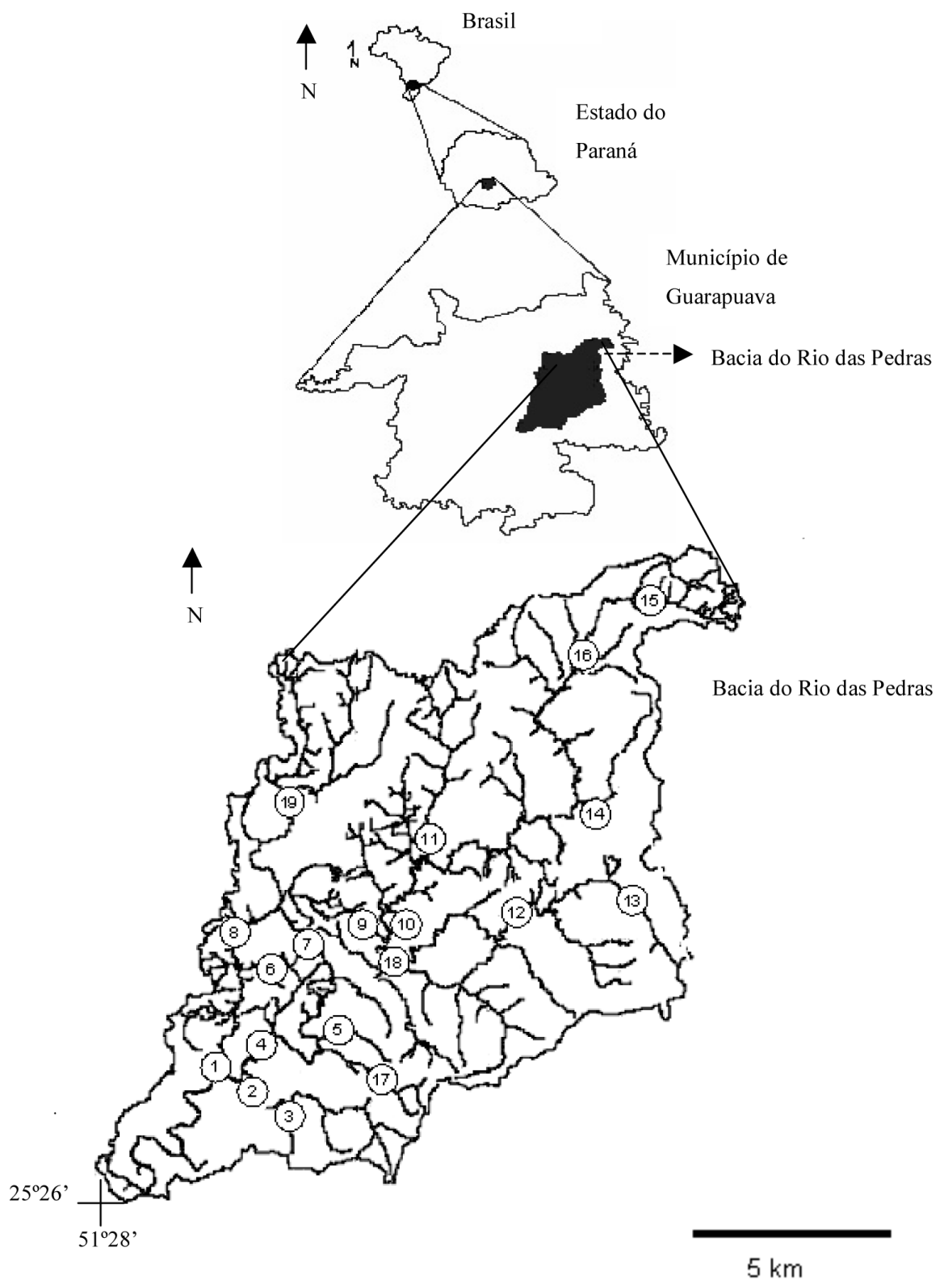

Figura 1. Localização geral da Bacia do Rio das Pedras, no município de Guarapuava, Estado do Paraná, Sul do Brasil e detalhe da Bacia do Rio das Pedras mostrando a localização dos 19 pontos de amostragem utilizados no estudo de levantamento florístico das comunidades de macroalgas. Barra de escala $=5 \mathrm{~km}$. 

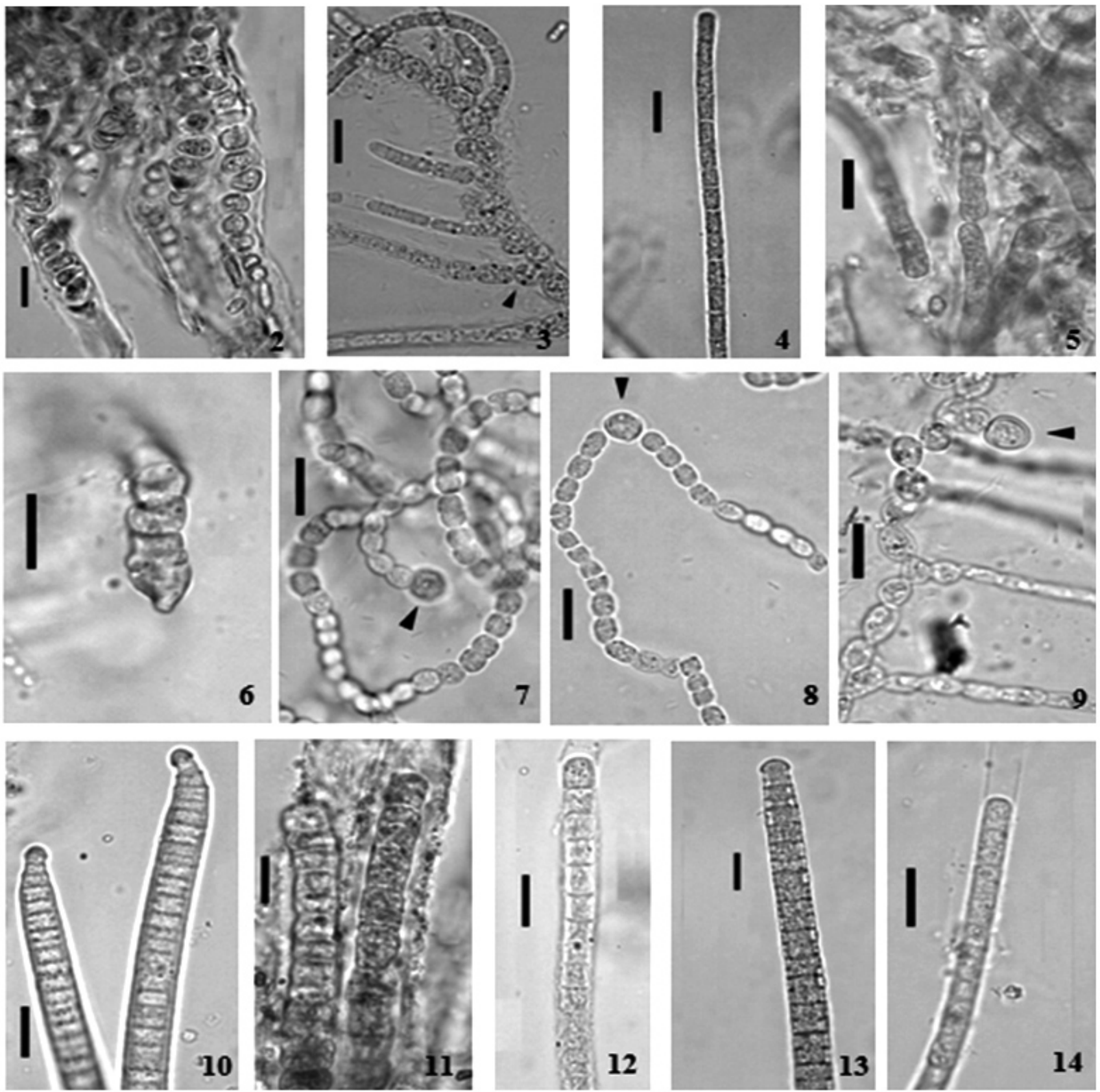

Figuras 2-14. Espécies de Cyanobacteria da bacia do rio das Pedras. 2. Chroococcopsis fluviatilis. 3. Fischerella ambigua, parte do filamento mostrando ramificação verdadeira (ponta de seta). 4. Geitlerinema amphibium. 5-6. Konvophoron schmidlei. 5. Vista geral da colônia. 6. Detalhe do filamento mostrando célula basal. 7-8. Nostoc verrucosum. 7. Detalhe da colônia mostrando filamento com heterocito basal (ponta de seta). 8. Filamento com heterocito intercalar (ponta de seta). 9. Nostochopsis lobatus, filamento com heterocito pedicelado (ponta de seta). 10. Phormidium autumnale. 11. P. puteale. 12. P. retzii. 13. P. schroederi. 14. P. willei, detalhe de um filamento. Barras de escala $=10 \mu \mathrm{m}$. 
Talo gelatinoso hemisféricos, firme, incrustante; azul escuro a verde; pseudofilamentos curtos, radiados ou paralelos; bainha espessa, incolor; células arredondadas ou poligonais, 4,5-8 um diâm., 4-8,5 $\mu \mathrm{m}$ compr., predominantemente mais longas do que largas, compr./diâm 0,6-1,4.

Distribuição na Bacia do Rio das Pedras: Ponto 7.

Características do riacho $(\mathrm{n}=1)$ : temperatura $=16,1^{\circ} \mathrm{C}$; condutividade $=28,8 \mu \mathrm{S} \mathrm{cm}{ }^{-1} ; \mathrm{pH}=7,5$; saturação de oxigênio $=71 \%$; turbidez $=2 \mathrm{NTU}$; velocidade da correnteza $=40,4 \mathrm{~cm} \mathrm{~s}^{-1}$.

Material examinado: BRASIL. PARANÁ: Guarapuava, Bacia do rio das Pedras, 26-VII-2004, R.A. Krupek et al. s.n. (SJRP28241).

Fischerella ambigua (Nägeli) Gomont, Journ. de Bot. 9: 52.1895 = Scytonema ambiguum Nägeli in Kützing, Spec. Alg.: 894. 1849.

Figura 3

Talo formado por filamentos emaranhados, verde-azulado, 5,3-7,8 um diâm; filamento principal com células subesféricas grandes, 3,3-5,6 $\mu$ m diâm.; ramificações abundantes em um dos lados do filamento; a base freqüentemente mais larga que o ápice; células das ramificações evidentemente menores do que as do filamento principal, quadráticas, 2-4,3 um diâm., 3,5-4,5 um compr., compr./diâm. 1-1,4; heterocitos cilíndricos, intercalares ou laterais.

Distribuição na Bacia do Rio das Pedras: Ponto 2.

Características do riacho $(\mathrm{n}=1)$ : temperatura $=11,9^{\circ} \mathrm{C}$; condutividade $=302 \mu \mathrm{S} \mathrm{cm}^{-1} ; \mathrm{pH}=7,6$; saturação de oxigênio $=99 \%$; turbidez $=2 \mathrm{NTU}$; velocidade da correnteza $=26,8 \mathrm{~cm} \mathrm{~s}^{-1}$.

Material examinado: BRASIL. PARANÁ: Guarapuava, Bacia do rio das Pedras, 26-VII-2004, R.A. Krupek et al. s.n. (SJRP28236).

Os espécimes desta população apresentaram diâmetro dos filamentos levemente menores que aquelas reportadas por Desikachary (1959, 6-9 um diâm.), entretanto, o material analisado esta de acordo com todos os demais caracteres diagnósticos apresentados na descrição da espécie. Assim, entendemos que esta pequena variação métrica observada não invalida a identificação especifica. Fischerella ambigua é reportada pela primeira vez em ambientes lóticos brasileiros.
Geitlerinema amphibium (Agardh ex Gomont) Anagnostidis, Pl. Syst. Evol.164: 38. 1989 三 Oscillatoria amphibia Agardh ex Gomnt, Ann. Sci. Nat. Ser. 7, 16: 221. 1892.

Figura 4

Talo formado por filamentos emaranhados, azul esverdeado; células mais longas que largas, 5-10 $\mu \mathrm{m}$ compr., 3-4 um diâm., compr./diâm. 1,4-2,8, conteúdo celular com 2 a 3 grânulos, às vezes nos septos; septos não constritos; célula apical cilíndrico-arredondada.

Distribuição na Bacia do Rio das Pedras: Ponto 17.

Características do riacho $(\mathrm{n}=1)$ : temperatura $=15,6^{\circ} \mathrm{C}$; condutividade $=240 \mu \mathrm{S} \mathrm{cm}^{-1} ; \mathrm{pH}=7,4$; saturação de oxigênio $=79 \%$; turbidez $=11$ NTU; velocidade da correnteza $=39,4 \mathrm{~cm} \mathrm{~s}^{-1}$.

Material examinado: BRASIL. PARANÁ: Guarapuava, Bacia do rio das Pedras, 21-VIII-2004, R.A. Krupek et al. s.n. (SJRP28251).

Desikachary (1959) refere-se a esta espécie como Oscillatoria amphibia Agardh ex Gomont, enquanto que Anagnostidis \& Komárek (1988) como Phormidium amphibium (Agardh ex Gomont) Anagnostidis \& Komárek. Entretanto, Anagnostidis (1989) estabeleceu o gênero Geitlerinema, transferindo para ele as espécies, até então, abrigadas no subgênero Geitlerinema de Phormidium. Geitlerinema amphibium, em particular, é descrita como sendo uma espécie que apresenta características morfológicas comparáveis à de outras espécies do gênero [(p.ex., G. ionicum (Skuja) Anagnostidis e G. unigranulatum (Singh) Komárek \& Azevedo)] (Romo et al. 1993, Komárek \& Anagnostidis 2005, Bittencourt-Oliveira et al. 2007). Contudo, a população encontrada na Bacia do Rio das Pedras apresenta características diagnósticas (incluindo dimensões celulares e número de grânulos de cianoficina junto ao septo celular) compatíveis com aquelas apresentadas na descrição da espécie proposta por Komárek \& Anagnostidis (2005).

Komvophoron schmidlei (Jaag) Anagnostidis \& Komárek, Algol. Studies 50-53: 373. 1988 三 Pseudanabaena schmidlei Jaag, Mitt. Naturf. Ges. Schaffhausen 14: 117. 1938.

Figuras 5-6

Talo formado por tricomas emaranhados, verdeazulado; com envelope mucilaginoso abundante envolvendo o conjunto de tricomas; tricomas 
fortemente curvados, curtos, entre 5 e 30 células; células curtas, moniliformes a cilíndrica, freqüentemente mais largas do que longas, 4,3-8,7(-10) um diâm., 4,7-7,8 um compr., compr./diâm. 0,6-1,0, conteúdo celular granulado, fortemente constrita nos septos, ocasionalmente com estreitamento na região mediana; célula apical cônico-alongada ou cônico-aguda; necrídios ausentes.

Distribuição na Bacia do Rio das Pedras: Ponto 3.

Características do riacho $(\mathrm{n}=1)$ : temperatura $=$ $12,6^{\circ} \mathrm{C}$; condutividade $=454 \mu \mathrm{S} \mathrm{cm}{ }^{-1} ; \mathrm{pH}=7,5$; saturação de oxigênio $=79,5 \%$; turbidez $=3 \mathrm{NTU}$; velocidade da correnteza $=38,3 \mathrm{~cm} \mathrm{~s}^{-1}$.

Material examinado: BRASIL. PARANÁ: Guarapuava, Bacia do rio das Pedras, 26-VII-2004, R.A. Krupek et al. s.n. (SJRP28237).

O gênero Komvophoron foi proposto por Anagnostidis \& Komárek (1988) para acomodar um grupo de espécies de caráter pseudoanabenóide portadoras de células mais ou menos esféricas ou em forma de barril. As características do material analisado concordam com a descrição apresentada por Komárek \& Anagnostidis (2005), diferindo apenas quanto à presença de um envelope mucilaginoso evidente. Os autores acima, fazem referência à ocorrência de tricomas curvados, assim como observado na Bacia do Rio das Pedras, entretanto, há diferenças quanto ao grau destas curvaturas (moderada para Komárek $\&$ Anagnostidis (2005) e forte para o nosso material). $\mathrm{Na}$ Europa, a espécie foi encontrada, entre outros ambientes, associada a substratos rochosos em riachos de águas límpidas e frias (Komárek \& Anagnostidis 2005), habitat semelhante ao encontrado no presente estudo. No Brasil, a presença de K. schmidlei foi registrada apenas uma única vez por Fonseca \& Rodrigues (2005), sendo que as medidas celulares (4-4,25 um diâm.; 2,9-3,8 um compr.) e o ambiente de ocorrência (lagoas de inundação) descritos diferem do observado para a Bacia do Rio das Pedras.

Nostoc verrucosum Vaucher ex Bornet \& Flahault, Ann. Sci. Nat. Ser. 7, Bot. 7: 203. 1886-1888.

Figuras 7-8

Talo formado por colônia mucilaginosa, firme, esférica a subesférica, com superfície verrucosa; verde-oliva a marrom esverdeado; tricomas flexuosos, densamente agregados; mucilagem espessa na região periférica e hialina e difluente na parte interna da colônia; células esféricas ou doliformes, 2,5-3,3 $\mu \mathrm{m}$ diâm., 2,5-4,9 um compr., compr./diâm. 1-2, conteúdo celular verde azulado, homogêneo; heterocisto subesférico 3,7-5,5 um diâm., acinetos não observados.

Distribuição na Bacia do Rio das Pedras: Ponto 4.

Características do riacho $(\mathrm{n}=1)$ : temperatura $=13,9^{\circ} \mathrm{C}$; condutividade $=248 \mu \mathrm{S} \mathrm{cm}^{-1} ; \mathrm{pH}=7,9$; saturação de oxigênio $=83 \%$; turbidez $=3 \mathrm{NTU}$; velocidade da correnteza $=58,7 \mathrm{~cm} \mathrm{~s}^{-1}$.

Material examinado: BRASIL. PARANÁ: Guarapuava, Bacia do rio das Pedras, 26-VII-2004, R.A. Krupek et al. s.n. (SJRP28238).

Esta espécie é raramente descrita como ocorrendo em ambientes de águas correntes, principalmente em regiões tropicais e subtropicais. No Brasil, particularmente, a espécie foi reportada por Peres et al. (2008) para riachos da Floresta Atlântica do Estado do Paraná.

Nostochopsis lobatus Wood ex Bornet \& Flahault, Ann. Sci. Nat. Ser. 5, Bot. 7: 203. 1886-1888.

\section{Figura 9}

Talo formado por colônias gelatinosas vesiculosas, verde-azulado; tricomas flexuosos, constritos nos septos com bainha hialina, homogênea; ramificações abundantes; células mais longas que largas, 4,1-6,1 $\mu \mathrm{m}$ diâm, 6,1-10,2 um compr., compr./diâm. 1-2,4; heterocistos arredondados, laterais ou intercalares, pedicelados, 6,1-8,2 $\mu \mathrm{m}$ diâm.

Distribuição na Bacia do Rio das Pedras: Ponto 17.

Características do riacho $(\mathrm{n}=1)$ : temperatura $=18{ }^{\circ} \mathrm{C}$; condutividade $=118 \mu \mathrm{S} \mathrm{cm}^{-1} ; \mathrm{pH}=7,1$; saturação de oxigênio $=69,5 \%$; turbidez $=11 \mathrm{NTU}$; velocidade da correnteza $=30,1 \mathrm{~cm} \mathrm{~s}^{-1}$.

Material examinado: BRASIL. PARANÁ: Guarapuava, Bacia do rio das Pedras, 21-VIII-2004, R.A. Krupek et al. s.n. (SJRP28251).

Phormidium autumnale (Agardh) Trevisan ex Gomont, Ann. Sci. Nat. Ser. 7, 16: 187. $1892 \equiv$ Oscillatoria autumnalis Agardh, Disp. Alg. Suec.: 36. 1812.

Figuras 10

Talo formado por tricomas emaranhados, azulesverdeado; bainha ausente; células predominantemente mais largas do que longas, com 4,9-9 $\mu$ m diâm., 2-4,9 um compr., comp./diâm 0,3-0,6; conteúdo celular 
homogêneo, septos não constritos, granulosos; célula apical arredondada a capitadas; necrídios e hormogônios presentes.

Distribuição na Bacia do Rio das Pedras: Ponto 8.

Características do riacho $(\mathrm{n}=1)$ : temperatura $=13,3{ }^{\circ} \mathrm{C}$; condutividade $=827 \mu \mathrm{S} \mathrm{cm}^{-1} ; \mathrm{pH}=7$; saturação de oxigênio $=76 \%$; turbidez $=2 \mathrm{NTU}$; velocidade da correnteza $=83,7 \mathrm{~cm} \mathrm{~s}^{-1}$.

Material examinado: BRASIL. PARANÁ: Guarapuava, Bacia do rio das Pedras, 26-VII-2004, R.A. Krupek et al. s.n. (SJRP28242).

Phormidium puteale (Montagne ex Gomont) Anagnostidis \& Komarek, Algol. Studies 5053: 408. 1988 E Lyngbya putealis Montagne ex Gomont, Ann. Sci. Nat. Ser. 7, 16: 143. 1892.

Figura 11

Talo formado por filamentos emaranhados, azul-esverdeado; filamentos 12-20 um diâm., bainha espessa; células predominantemente mais largas

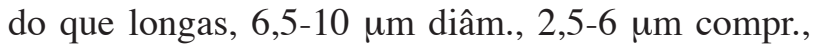
compr./diâm. 0,3-0,6; conteúdo celular com grânulos, não constritos nos septos; célula apical arredondada.

Distribuição na Bacia do Rio das Pedras: Ponto 7.

Características do riacho $(\mathrm{n}=1)$ : temperatura $=16,1^{\circ} \mathrm{C}$; condutividade $=28,8 \mu \mathrm{S} \mathrm{cm} \mathrm{cm}^{-1} ; \mathrm{pH}=7,5$; saturação de oxigênio $=71 \%$; turbidez $=2 \mathrm{NTU}$; velocidade da correnteza $=40,4 \mathrm{~cm} \mathrm{~s}^{-1}$.

Material examinado: BRASIL. PARANÁ: Guarapuava, Bacia do rio das Pedras, 26-VII-2004, R.A. Krupek et al. s.n. (SJRP28241).

Phormidium retzii Gomont, Ann. Sci. Nat., Ser. 7, 15: 175.1892.

Figura 12

Talo formado por filamentos emaranhados, azulesverdeado ou acastanhado; filamentos 3,5-9 $\mu \mathrm{m}$ diâm., bainha hialina; células predominantemente mais longas do que largas, 4,3-10,2 $\mu$ m diâm., 3,2-8,2 um compr., compr./diâm. 0,4-1,5; conteúdo celular homogêneo, grânulos ausentes, não constrita nos septos; célula apical cilíndrico-arredondada, 4-8,7 $\mu \mathrm{m}$ compr.; necrídios presentes.
Distribuição na Bacia do Rio das Pedras: Pontos 05, 06, 07, 09, 11, 14, 15, 16 e 19.

Características dos riachos $(\mathrm{n}=9)$ : temperatura $=$ $12,3-16,1^{\circ} \mathrm{C}(\overline{\mathrm{x}}=13,8)$; condutividade $=25,6-773 \mu \mathrm{S}$ $\mathrm{cm}^{-1}(\overline{\mathrm{X}}=303,3) ; \mathrm{pH}=6,8-7,6(\overline{\mathrm{X}}=7,2)$; saturação de oxigênio $=61 \%-91 \%(\bar{X}=74,5)$; turbidez $=1-5$ NTU ( $\bar{x}=3)$; velocidade da correnteza $=8,9-74 \mathrm{~cm}$ $\mathrm{s}^{-1}(\overline{\mathrm{X}}=44,3)$.

Material examinado: BRASIL. PARANÁ: Guarapuava, Bacia do rio das Pedras, 26-VII-2004, R.A. Krupek et al. s.n. (SJRP28239); idem, 26-VII-2004, R.A. Krupek et al. s.n. (SJRP28240); idem, 26-VII-2004, R.A. Krupek et al. s.n. (SJRP28241); idem, 28-VII-2004, R.A. Krupek et al. s.n. (SJRP28243); idem, 28-VII2004, R.A. Krupek et al. s.n. (SJRP28245); idem, 28-VII-2004, R.A. Krupek et al. s.n. (SJRP28248); idem, 28-VII-2004, R.A. Krupek et al. s.n. (SJRP28249); idem, 28-VII-2004, R.A. Krupek et al. s.n. (SJRP28250); idem, 21-VIII-2004, R.A. Krupek et al. s.n. (SJRP28253).

Phormidium cf. schroederi (Borge) Anagostidis \& Komárek, Algol. Studies 50-53: 406.1988 三 Oscillatoria schroederi Borge, Hedwigia 68: 109. 1928.

Figura 13

Talo formado por filamentos emaranhados, verdeazulado; tricomas retos ou levemente ondulados; células predominantemente mais largas do que longas; 7,5-9,5 um diâm., 3,5-6,5 um compr., compr./ diâm. 0,4-0,7; conteúdo celular com fina granulação; não constritas nos septos; célula apical com leve espessamento da parede externa.

Distribuição na Bacia do Rio das Pedras: Ponto 17.

Características do riacho $(n=1)$ : temperatura $=18,9^{\circ} \mathrm{C}$; condutividade $=381 \mu \mathrm{S} \mathrm{cm}^{-1} ; \mathrm{pH}=7,2$; saturação de oxigênio $=75 \%$; turbidez $=9 \mathrm{NTU}$; velocidade da correnteza $=30,5 \mathrm{~cm} \mathrm{~s}^{-1}$.

Material examinado: BRASIL. PARANÁ: Guarapuava, Bacia do rio das Pedras, 21-VIII-2004, R.A. Krupek et al. s.n. (SJRP28251).

Nossos espécimes assemelham-se bastante à $P$. schroederi, apresentando relativa conformidade com as descrições de Komárek \& Anagnostidis (2005) e Branco et al. (1999). Entretanto, embora as medidas 
de comprimento celular sejam muito semelhantes, as de diâmetro celular observadas no presente estudo são maiores do que aquelas reportadas por Komárek \& Anagnostidis (2005) e Branco et al. (1999) (5,77,2 $\mu \mathrm{m}$ e 5,5-7,2 $\mu \mathrm{m}$, respectivamente). Em adição, os tricomas coletados na Bacia do Rio das Pedras apresentam um espessamento da membrana externa da célula apical, característica não reportada nos estudos acima citados. Komárek \& Anagnostidis (2005) comentam sobre a necessidade de revisão das populações brasileiras e africanas.

Phormidium willei (Gardner) Anagnostidis \& Komárek, Algol. Studies 50-53: 404.1998 三 Oscillatoria willei Gardner, Mem. N. Y. Bot. Gdn. 7: 3. 1927.

Figura 14-15

Talo formado por filamentos emaranhados, azul-esverdeado ou azul claro; tricomas com bainha facultativa; células predominantemente mais largas do que longas, 3,2-4,5 $\mu$ m diâm., 2-4,9 um compr., compr./diâm. 0,5-1,5; conteúdo celular homogêneo, não constrita nos septos; célula apical cônico-arredondada, 3,5-5,5 um compr.; necrídios e hormogônios presentes.

Distribuição na Bacia do Rio das Pedras: Ponto 8.

Características do riacho $(\mathrm{n}=1)$ : temperatura $=13,3{ }^{\circ} \mathrm{C}$; condutividade $=827 \mu \mathrm{S} \mathrm{cm}{ }^{-1} ; \mathrm{pH}=7$; saturação de oxigênio $=76 \%$; turbidez $=2 \mathrm{NTU}$; velocidade da correnteza $=83,7 \mathrm{~cm} \mathrm{~s}^{-1}$.

Material examinado: BRASIL. PARANÁ: Guarapuava, Bacia do rio das Pedras, 26-VII-2004, R.A. Krupek et al. s.n. (SJRP28242).

O diâmetro celular de nossos espécimes é pouco maior que o referido originalmente por Komárek \& Anagnostidis (2005) (2,4-2,7 $\mu \mathrm{m})$, entretanto concordam com aqueles descritos por Branco et al. (1999) (2,5-4,4 $\mu \mathrm{m})$, para material do Estado de São Paulo. Branco et al. (1999) comentam a dificuldade em separar esta espécie de Jaaginema homogeneum (Frémy) Anagostidis et Komárek, espécie que apresenta, ocasionalmente, uma bainha de mucilagem difusa. Drouet (1937) e Desikachary (1959) consideram J. homogeneum (como Oscillatoria homogenea) dentro de $P$. willei (como Oscillatoria willei).
Symplocastrum cf. friesii Agardh ex Kirchner in Engler \& Prantl., Natürlichen Planzenfam. $1\left(1^{\mathrm{a}}\right): 45.1900$.

Figura 16

Talo formado por tricomas inclusos em uma bainha comum, verde-amarelado; bainha firme, espessa e hialina, fechada no ápice; 2 a mais de 10 tricomas por bainha; células 3,2-7,5 $\mu \mathrm{m}$ diâm., 3,3-10 um compr., mais longas do que largas, compr./diâm. 0,6-1,5, conteúdo celular granuloso; constritas nos septos; célula apical cônica com ápice arredondado.

Distribuição na Bacia do Rio das Pedras: Pontos 4 e 13 .

Características dos riachos $(\mathrm{n}=2)$ : temperatura $=$ $12,7-13,9{ }^{\circ} \mathrm{C}$; condutividade $=248-451 \mu \mathrm{S} \mathrm{cm}{ }^{-1} ; \mathrm{pH}$ =7-7,9; saturação de oxigênio $=76 \%-83 \%$; turbidez $=2-3 \mathrm{NTU}$; velocidade da correnteza $=58,7-62,5$ $\mathrm{cm} \mathrm{s}^{-1}$.

Material examinado: BRASIL. PARANÁ: Guarapuava, Bacia do rio das Pedras, 26-VII-2004, R.A. Krupek et al. s.n. (SJRP28238); idem, 28-VII-2004, R.A. Krupek et al. s.n. (SJRP28247).

O material analisado apresenta medidas de diâmetro pouco maiores que aquelas apresentadas na descrição de Komárek \& Anagnostidis (2005) para $S$. friesii (3-6,6 $\mu \mathrm{m})$. Os registros de ocorrência da espécie sugerem que hábito preferencial seja o aerofítico e/ou terrestre, entretanto esta espécie já foi descrita para os Estados de São Paulo (Branco et al. 1999, como Schizothrix friesii) e Paraná (Peres et al. 2008). Por outro lado, existem registros da espécie em águas correntes no Brasil (p.ex., Branco et al. 1999) que, segundo Komárek \& Anagnostidis (2005), carecem de revisão.

Stigonema robustum Gardner, Univ. Calif. Publ. Bot. 14(1): 9. 1927.

Figura 17

Talo constituído por filamentos emaranhados formando tufos, azul escuro; filamentos 80-137,5 um diâm., bainha relativamente fina, lamelada e amarelada; tricomas prioritariamente multicelulares; células sub-quadráticas, 10-15 $\mu \mathrm{m}$ compr., 6-12 um diâm., compr./diâm. 0,8-1,6; conteúdo celular homogêneo; ramificações densamente agrupadas, heterocistos não observados. 

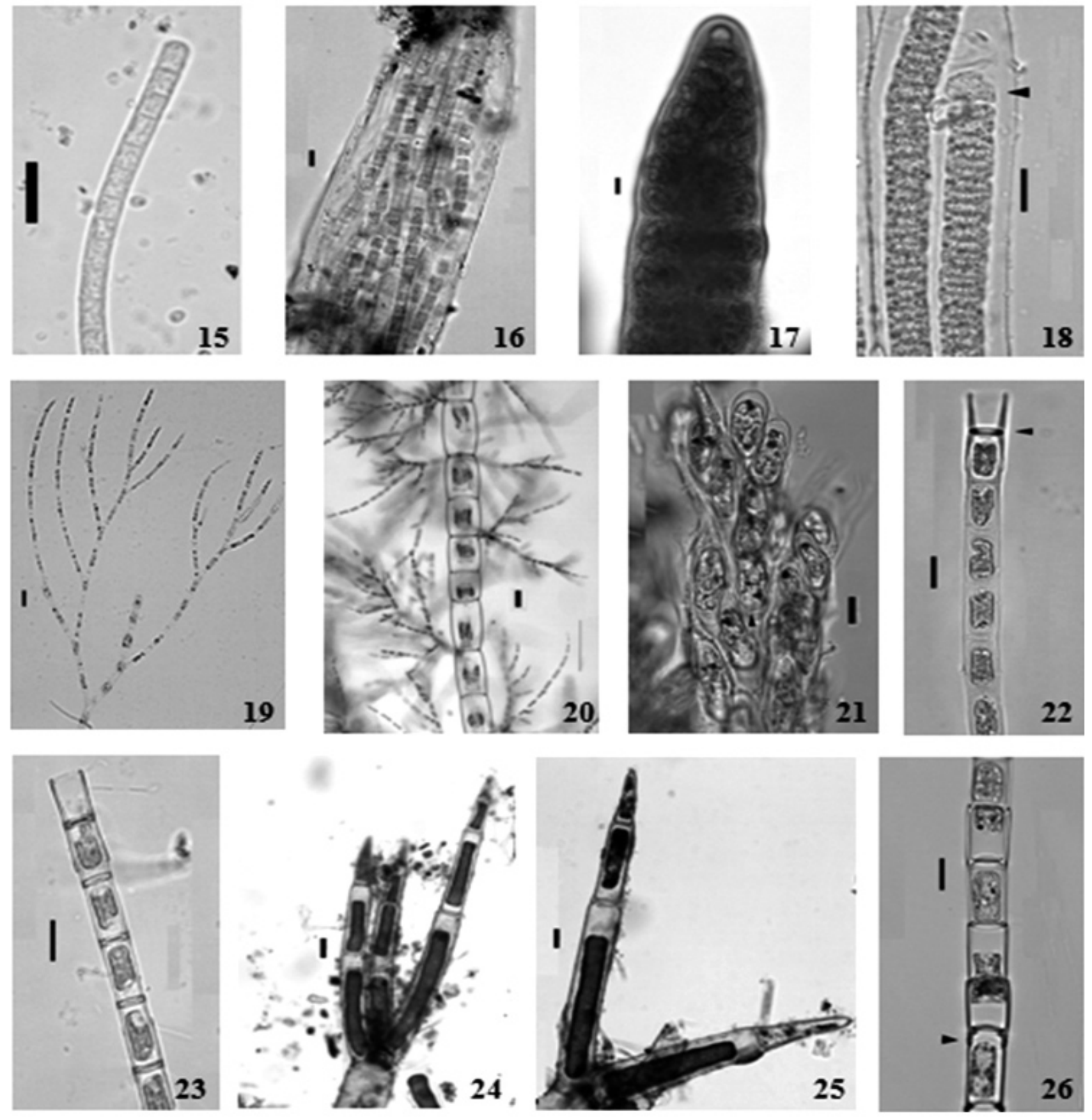

Figuras 15-26. Espécies de Cyanobacteria e Chlorophyta da bacia do rio das Pedras. 15. Phormidium willei, detalhe de um tricoma sem bainha. 16. Symplocastrum cf. friessi. 17. Stigonema robustum. 18. Tolypothrix byssoidea, filamento mostrando falsa ramificação com heterocito basal (ponta de seta). 19. Chaetophora elegans. 20. Draparnaldia mutabilis. 21. Ecballocystis pulvinata var. pulvinata, detalhe da colônia mostrando parede celular gelatinizada de antigas gerações com arranjo estratificado (ponta de seta). 22. Microspora quadrata, ápice do filamento mostrando a parede em forma de $\mathrm{H}$ (ponta de seta). 23. Microspora stagnorum, detalhe dos dáctilos tri e tetra-celulados. 24-25. Nitella sp. 24. Detalhe dos dáctilos bi e tri-celulados. 26-Oedogonium sp. Detalhe do filamento com estrias de crescimento (ponta de seta). Barras de escala $=10 \mu \mathrm{m}(15-19,21-23,26) ; 50 \mu \mathrm{m}(20,24,25)$. 
Distribuição na Bacia do Rio das Pedras: Ponto 16.

Características do riacho $(\mathrm{n}=1)$ : temperatura $=12,8^{\circ} \mathrm{C}$; condutividade $=267 \mu \mathrm{S} \mathrm{cm}^{-1} ; \mathrm{pH}=7,2$; saturação de oxigênio $=75 \%$; turbidez $=3 \mathrm{NTU}$; velocidade da correnteza $=51,0 \mathrm{~cm} \mathrm{~s}^{-1}$.

Material examinado: BRASIL. PARANÁ: Guarapuava, Bacia do rio das Pedras, 28-VII-2004, R.A. Krupek et al. s.n. (SJRP28250).

Tolypothrix byssoidea (Hassal) Kirchner, Krypt. Fl. Schles.: 231. 1878 = Hassalia byssoidea Hassal, Brit. Freshw. Alg. 1: 233. 1845.

Figura 18

Talo constituído por filamentos formando tufos, verde escuro; filamentos arranjados de forma paralela, 9,8-19 um diâm.; falsas ramificações curtas, raras; bainha homogênea, incolor; tricomas constritos nos septos; células 6,5-14,7 um diâm., 2-4,5 um compr., compr./diâm. 0,3-0,7, conteúdo celular homogêneo, verde-azulado; heterocisto basal, arredondado, 6,59,8 um diâm.

Distribuição na Bacia do Rio das Pedras: pontos 05, 10,12 e 16.

Características dos riachos $(\mathrm{n}=4)$ : temperatura $=$ $13,1-13,9^{\circ} \mathrm{C}(\overline{\mathrm{X}}=13,2)$; condutividade $=124-535 \mu \mathrm{S}$ $\mathrm{cm}^{-1}(\overline{\mathrm{X}}=273,5) ; \mathrm{pH}=7,1-7,6(\overline{\mathrm{X}}=7,2)$; saturação de oxigênio $=73,5 \%-84,5 \%(\bar{X}=78)$; turbidez $=2-4$ NTU $(\bar{x}=3)$; velocidade da correnteza $=51,0-73,7$ $\mathrm{cm} \mathrm{s}^{-1}(\bar{X}=65,6)$.

Material examinado: BRASIL. PARANÁ: Guarapuava, Bacia do rio das Pedras, 26-VII-2004, R.A. Krupek et al. s.n. (SJRP282539); idem, 28-VII-2004, R.A. Krupek et al. s.n. (SJRP28244); idem, 28-VII-2004, R.A. Krupek et al. s.n. (SJRP28246); idem, 28-VII2004, R.A. Krupek et al. s.n. (SJRP28250).

Tolypothrix byssoidea tem sido reportada para ambientes sub-aéreos (Sant'Anna 1988). Os espécimes descritos em Sant'Anna (1988) apresentam valores métricos de diâmetro do filamento e tricoma (10-14 $\mu \mathrm{m}$ e 7-11 $\mu \mathrm{m}$, respectivamente) um pouco menores do que os observados no presente estudo. Entretanto, todas as características morfológicas dos filamentos e dos tricomas dos espécimes estudados estão de acordo com a descrição oferecida por Sant'Anna (1988).

\section{CHLOROPHYTA}

Chaetophora elegans (Roth) C. Agardh, Disp. Alg. Suec.: 42.1812 =Rivularia elegans Roth, Neue Beitr. Bot. 1: 269.1802.

Figura 19

Talo formado por filamentos ramificados envolvidos em matriz gelatinosa frouxa, verde claro, 0,5-2 cm diâm.; filamentos eretos di ou tricotomicamente ramificados; ramos laterais frouxos e espalhados, fasciculados próximos à periferia; células do eixo apical cilíndricas, 23,7-60,0 $\mu$ m compr., 7,511,2 $\mu \mathrm{m}$ diâm., compr./diâm. 2,6-5,3; sistema basal composto de filamento prostrado ramificado com células cilíndricas, produzindo filamentos eretos e rizóides.

Material examinado: BRASIL. PARANÁ: Guarapuava, Bacia do rio das Pedras, 21-VIII-2004, R.A. Krupek et al. s.n. (SJRP28251).

Distribuição na Bacia do Rio das Pedras: Ponto 17.

Características do riacho $(\mathrm{n}=1)$ : temperatura $=20,1^{\circ} \mathrm{C}$; condutividade $=330 \mu \mathrm{S} \mathrm{cm}^{-1} ; \mathrm{pH}=7,6$; saturação de oxigênio $=67 \%$; turbidez $=2 \mathrm{NTU}$; velocidade da correnteza $=23,1 \mathrm{~cm} \mathrm{~s}^{-1}$.

Draparnaldia mutabilis (Roth) Bory, Ann. Mus. National d'Hist. Natur. 12: 405. 1808 = Conferva mutabilis Roth, Cat. Bot. 1: 197. 1797.

Figura 20

Talo formado por filamentos ramificados envolvidos por uma leve e fluida mucilagem, verde claro; eixo principal distinto com células cilíndricas infladas, 51,2-143,5 $\mu \mathrm{m}$ compr., 32,8-79,9 $\mu \mathrm{m}$ diâm.; fascículo lateral sem eixo principal distinto, ramificações di ou tricotômicas, alternadas ou opostas; células dos ramos laterais cilíndricas, 16,4-65,6 um compr., 6,1-41 um diâm.; células terminais dos fascículos laterais acuminadas ou arredondadas; pêlos multicelulares presentes; sistema basal formado por uma profusa massa de rizóides ramificados.

Distribuição na Bacia do Rio das Pedras: Ponto 19

Características do riacho $(n=1)$ : temperatura $=15,2^{\circ} \mathrm{C}$; condutividade $=25,6 \mu \mathrm{S} \mathrm{cm}{ }^{-1} ; \mathrm{pH}=7,5$; saturação de oxigênio $=61 \%$; turbidez $=5 \mathrm{NTU}$; velocidade da correnteza $=47,9 \mathrm{~cm} \mathrm{~s}^{-1}$. 
Material examinado: BRASIL. PARANÁ: Guarapuava, Bacia do rio das Pedras, 21-VIII-2004, R.A. Krupek et al. s.n. (SJRP28253).

Ecbalocystis pulvinata Bohlin var. pulvinata, Sv. Vet.-Akad. Hand. 23 (7): 7. 1897.

Figura 21

Talo formado por colônia constituída por numerosos ramos eretos, dendróides, fortemente agregados; base da colônia obcônica ou alargada; células elípticas ou obcônicas, (4,2-)6,5-9,8 $\mu$ m diâm., 14,7-22,9 um comp., compr./diâm. 1,6-3; cloroplastos 4-8, parietal, discóide, somente duas células filhas formadas após a divisão celular; paredes gelatinizadas das gerações mais velhas acumulam-se sob as células resultando em arranjo estratificado típico.

Distribuição na Bacia do Rio das Pedras: Ponto 4.

Características do riacho $(\mathrm{n}=1)$ : temperatura $=13,9^{\circ} \mathrm{C}$; condutividade $=248 \mu \mathrm{S} \mathrm{cm}^{-1} ; \mathrm{pH}=7,9$; saturação de oxigênio $=83 \%$; turbidez $=3 \mathrm{NTU}$; velocidade da correnteza $=58,7 \mathrm{~cm} \mathrm{~s}^{-1}$.

Material examinado: BRASIL. PARANÁ: Guarapuava, Bacia do rio das Pedras, 26-VII-2004, R.A. Krupek et al. s.n. (SJRP28238).

Microspora quadrata Hazen, Mem. Torrey Bot. Cl. 11: 178. 1887.

Figura 22

Talo constituído por filamentos densos emaranhados; filamentos longos, com mais de 100 células; células cúbicas ou em forma de barril,

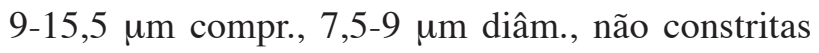
nos septos; parede celular com até $1 \mu \mathrm{m}$ de espessura; estruturas em forma de $\mathrm{H}$ visíveis através do filamento; cloroplasto em forma de lâmina.

Distribuição na Bacia do Rio das Pedras: Ponto 18.

Características do riacho $(\mathrm{n}=1)$ : temperatura $=14,7^{\circ} \mathrm{C}$; condutividade $=33,1 \mu \mathrm{S} \mathrm{cm}^{-1} ; \mathrm{pH}=7,7$; saturação de oxigênio $=67 \%$; turbidez $=21 \mathrm{NTU}$; velocidade da correnteza $=41,9 \mathrm{~cm} \mathrm{~s}^{-1}$.

Material examinado: BRASIL. PARANÁ: Guarapuava, Bacia do rio das Pedras, 21-VIII-2004, R.A. Krupek et al. s.n. (SJRP28252).
Microspora stagnorum (Kützing) Lagerheim, Ber. Dt. Bot. Ges. 5: 414. 1887 = Conferva tenerrima f. stagnorum Kützing, Alg. Aq. Dulc. Germ. 6: 4. 1833.

Figura 23

Talo constituído por filamentos densos emaranhados; filamentos longos, com mais de 100 células, cilíndricas ou cúbicas; células 6,5-9 ㅆm diâm., 9,8-17 $\mu$ m compr., não constritas nos septos; parede celular com até $1 \mu \mathrm{m}$ de espessura, estruturas em forma de $\mathrm{H}$ pouco visíveis em células intactas.

Distribuição na Bacia do Rio das Pedras: Ponto 6.

Características do riacho $(n=1)$ : temperatura $=15,5^{\circ} \mathrm{C}$; condutividade $=773 \mu \mathrm{S} \mathrm{cm}^{-1} ; \mathrm{pH}=7,5$; saturação de oxigênio $=67 \%$; turbidez $=3 \mathrm{NTU}$; velocidade da correnteza $=35,5 \mathrm{~cm} \mathrm{~s}^{-1}$.

Material examinado: BRASIL. PARANÁ: Guarapuava, Bacia do rio das Pedras, 26-VII-2004, R.A. Krupek et al. s.n. (SJRP28240).

\section{Nitella sp.}

Figuras 24-25

Talo formado por filamentos verticilados e corticados, desprovidos de incrustação calcárea; internós unicelulares nus e variando entre 9 e 18 cm compr.; verticilos estéreis bem desenvolvidos; verticilos férteis reduzidos, formando capítulos; râmulos verticilados estéreis 2-furcados; dáctilos 2-4 celulados, 42,1-77,2 um diâm, 135,2-451,1 um compr.; glóbulos pedunculados, 89,6-119,8 um diâm.; núculas não observadas.

Distribuição na Bacia do Rio das Pedras: Ponto 14.

Características do riacho $(\mathrm{n}=1)$ : temperatura $=13,7^{\circ} \mathrm{C}$; condutividade $=147 \mu \mathrm{S} \mathrm{cm}^{-1} ; \mathrm{pH}=6,8$; saturação de oxigênio $=81 \%$; turbidez $=1 \mathrm{NTU}$; velocidade da correnteza $=34,3 \mathrm{~cm} \mathrm{~s}^{-1}$.

Material examinado: BRASIL. PARANÁ: Guarapuava, Bacia do rio das Pedras, 28-VII-2004, R.A. Krupek et al. s.n. (SJRP28248).

As estruturas de reprodução femininas são indispensáveis para identificação das espécies do gênero Nitella. Assim, a identificação em nível de espécie do material coletado na Bacia do Rio das Pedras não foi possível, pois foram observadas apenas plantas masculinas nas amostras analisadas. 

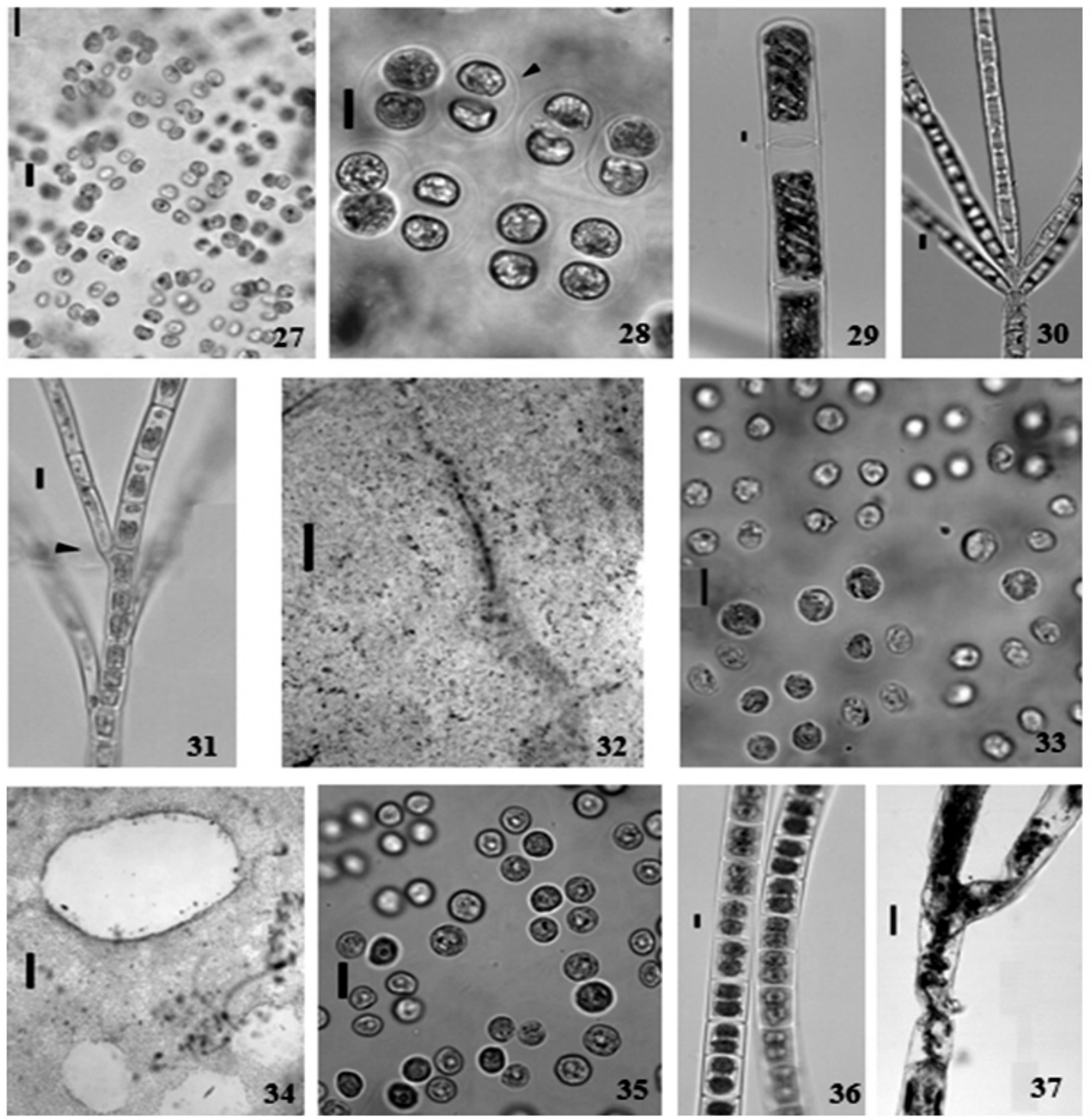

Figuras 27-37. Espécies de Chlorophyta e Heterokontophyta da bacia do rio das Pedras. 27-28. Palmella mucosa. 27. Vista geral da colônia. 28. Detalhe da colônia mostrando as células com envelope de mucilagem (ponta de seta). 29. Spirogyra sp. 30. Stigeoclonium amoenum, eixo principal mostrando duas células curtas com ramos laterais consecutivos. 31. Stigeoclonium helveticum, sistema ereto mostrando células de ramificação similar em forma e tamanho às outras do eixo principal (ponta de seta). 32-33. Tetraspora gelatinosa. 32. Vista geral da colônia sem perfuração. 33. Detalhe da colônia mostrando células arranjadas em grupos de quatro. 34-35. Tetraspora lubrica. 34. Vista geral da colônia perfurada. 35. Detalhe da colônia mostrando as células arranjadas em grupos de quatro. 36. Zygnema sp. 37. Vaucheria sp., detalhe do filamento cenocítico. Barras de escala = $10 \mu \mathrm{m}(27-31,33,35,37) ; 50 \mu \mathrm{m}(36) ; 200 \mu \mathrm{m}(32,34)$. 


\section{Oedogonium sp.}

Figura 26

Filamentos com células cilíndricas, levemente constritas nos septos, 21,3 - 164,6 um compr., 14,7 52,6 um diâm. Oogônio e anterídio não observados.

Distribuição na Bacia do Rio das Pedras: 6 e 10.

Características dos riachos $(\mathrm{n}=2)$ : temperatura $=$ $13,1-15,5{ }^{\circ} \mathrm{C}$; condutividade $=124-773 \mu \mathrm{mS} \mathrm{cm}{ }^{-1}$; $\mathrm{pH}=7,2-7,5$; saturação de oxigênio $=67 \%-84,5 \%$; turbidez $=2,91-2,95 \mathrm{NTU}$; velocidade da correnteza $=35,5-73,7 \mathrm{~cm} \mathrm{~s}^{-1}$.

Material examinado: BRASIL. PARANÁ: Guarapuava, Bacia do rio das Pedras, 26-VII-2004, R.A. Krupek et al. s.n. (SJRP28240); idem, 28-VII-2004, R.A. Krupek et al. s.n. (SJRP28244).

Neste gênero as características das estruturas sexuadas (oogônios e anterídios) são indispensáveis para a identificação das espécies, sendo, por outro lado, as características vegetativas pouco importantes neste contexto. No material coletado nos riachos da Bacia do Rio das Pedras não foram encontradas populações férteis e por isso não foi possível a identificação em nível específico.

Palmella mucosa Kützing, Phyc. Gen. 172: 3. 1843.

Figura 27-28

Talo formado por colônias macroscópicas, formando uma massa gelatinosa verde, globosa, irregularmente lobada; células elipsóides a esféricas, dispostas em grupos de 2 ou 4, com envelope individual de mucilagem, 8,7-13,7 $\mu \mathrm{m}$ diâm.; cloroplasto copuliforme com um pirenóide grande, um por célula; envelope adicional de mucilagem envolvendo as células filhas depois da divisão celular.

Distribuição na Bacia do Rio das Pedras: Ponto 17.

Características do riacho $(\mathrm{n}=1)$ : temperatura $=20,1^{\circ} \mathrm{C}$; condutividade $=410 \mu \mathrm{S} \mathrm{cm}^{-1} ; \mathrm{pH}=7,4$; saturação de oxigênio $=61,5 \%$; turbidez $=4 \mathrm{NTU}$; velocidade da correnteza $=30,1 \mathrm{~cm} \mathrm{~s}^{-1}$.

Material examinado: BRASIL. PARANÁ: Guarapuava, Bacia do rio das Pedras, 21-VIII-2004, R.A. Krupek et al. s.n. (SJRP28251).

Alguns autores consideram Palmella um gênero monoespecífico (P. aurantia), ocorrendo basicamente em ambientes sub-aéreos. Entretanto, Komárek
\& Fott (1983) descreveram e ilustraram três espécies diferentes, entre elas $P$. mucosa. Sheath \& Cole (1992) encontraram esta espécie em ambientes de águas correntes da América do Norte. Nossos espécimes apresentam todos os caracteres diagnósticos descritos para $P$. mucosa por Komárek \& Fott (1983). Palmella mucosa é reportada pela primeira vez para o Brasil.

\section{Spirogyra sp.}

Figura 29

Filamentos com células cilíndricas, 32,8 - 50,8 um compr., 16,4 - 21,3 um diâm. Zigósporos não observados.

Distribuição na Bacia do Rio das Pedras: Ponto 16.

Características do riacho $(\mathrm{n}=1)$ : temperatura $=12,8^{\circ} \mathrm{C}$; condutividade $=267 \mu \mathrm{S} \mathrm{cm}^{-1} ; \mathrm{pH}=7,2$; saturação de oxigênio $=75 \%$; turbidez $=3 \mathrm{NTU}$; velocidade da correnteza $=51,0 \mathrm{~cm} \mathrm{~s}^{-1}$.

Material examinado: BRASIL. PARANÁ: Guarapuava, Bacia do rio das Pedras, 28-VII-2004, R.A. Krupek et al. s.n. (SJRP28250).

Neste gênero as características das estruturas sexuadas (zigósporos) são essenciais para a identificação das espécies, sendo, por outro lado, as características vegetativas pouco importantes neste contexto. No material coletado nos riachos da Bacia do Rio das Pedras não foram encontradas populações férteis e por isso não foi possível a identificação em nível específico.

Stigeoclonium amoenum Kutzing, Phyc. Gen.: 1918. 1845.

Figura 30

Talo formado por tufos heterotríquios, verde claro; sistema ereto bem desenvolvido; sistema prostrado reduzido composto exclusivamente de rizóides; células do eixo principal diferenciada em dois tipos: curtas e longas, cilíndricas 6,5-17,5 $\mu \mathrm{m}$ de diâm., 22,9-150 um compr.; ramificações opostas ou alternadas; células dos ramos laterais 3,2-6,5 $\mu \mathrm{m}$ diâm. 9,8-22,9 $\mu \mathrm{m}$ compr.

Distribuição na Bacia do Rio das Pedras: Pontos 14 e 17.

Características dos riachos $(\mathrm{n}=2)$ : temperatura $=$ $13,7-15,6{ }^{\circ} \mathrm{C}$; condutividade $=147-240 \mu \mathrm{S} \mathrm{cm}^{-1} ; \mathrm{pH}$ 
$=6,8-7,4$; saturação de oxigênio $=79 \%-81 \%$; turbidez

=1-11 NTU; velocidade da correnteza $=34,3-39,4$ $\mathrm{cm} \mathrm{s}^{-1 \beta}$.

Material examinado: BRASIL. PARANÁ: Guarapuava, Bacia do rio das Pedras, 28-VII-2004, R.A. Krupek et al. s.n. (SJRP28248); idem, 21-VIII-2004, R.A. Krupek et al. s.n. (SJRP28251).

Stigeoclonium helveticum Vischer, Bot. Zentralbl. 51: 56. 1993.

Figura 31

Talo formado por tufos heterotriquios, verde claro; sistema ereto bem desenvolvido; sistema prostrado reduzido composto de curtos rizóides, originados da base dos filamentos eretos; células do eixo principal semelhantes em forma e tamanho, cilíndricas 1012,5 $\mu \mathrm{m}$ diâm., 18,7-53,7 um compr.; ramificação oposta ou alternada, ramificações draparnaldioides freqüentes; células do ramo lateral 5-7,5 $\mu \mathrm{m}$ diâm., 11,2-20 $\mu \mathrm{m}$ compr.

Distribuição na Bacia do Rio das Pedras: Ponto 16.

Características do riacho $(\mathrm{n}=1)$ : temperatura $=12,8^{\circ} \mathrm{C}$; condutividade $=267 \mu \mathrm{S} \mathrm{cm}^{-1} ; \mathrm{pH}=7,2 ;$ saturação de oxigênio $=75 \%$; turbidez $=3 \mathrm{NTU}$; velocidade da correnteza $=51,0 \mathrm{~cm} \mathrm{~s}^{-1}$.

Material examinado: BRASIL. PARANÁ: Guarapuava, Bacia do rio das Pedras, 28-VII-2004, R.A. Krupek et al. s.n. (SJRP28250).

Tetraspora gelatinosa (Vaucher) Desvaux, Obs. Pl. Angers.: 18. 1818 = Ulva gelatinosa Vaucher, Hist. Conf.: 244.1803.

Figuras 32-33

Talo constituído de colônia tubular, sem perfuração, composta por células esféricas arranjadas em grupos de 2-4, envolta por copiosa matriz mucilaginosa; cloroplasto poculiforme, com um pirenóide; células 6,2-10 um diâm., com dois pseudoflagelos, sem envelope individual de mucilagem.

Distribuição na Bacia do Rio das Pedras: Ponto 18.

Características do riacho $(\mathrm{n}=1)$ : temperatura $=14,7^{\circ} \mathrm{C}$; condutividade $=33,1 \mu \mathrm{S} \mathrm{cm}^{-1} ; \mathrm{pH}=7,7$; saturação de oxigênio $=67 \%$; turbidez $=21 \mathrm{NTU}$; velocidade da correnteza $=41,9 \mathrm{~cm} \mathrm{~s}^{-1}$.
Material examinado: BRASIL. PARANÁ: Guarapuava, Bacia do rio das Pedras, 21-VIII-2004, R.A. Krupek et al. s.n. (SJRP28252).

Tetraspora lubrica (Roth) C. Agardh, Syst. Algar. 1824 =Ulva lubrica Roth, Cat. Bot. 1: 204. 1797.

Figuras 34-35

Talo constituído de colônia tubular ou irregular, perfurada, composta de células esféricas arranjadas em grupos de 2-4, embebida em matriz mucilaginosa; cloroplasto poculiforme, com um pirenóide; células 5-8,7 $\mu$ m diâm., com 2 pseudoflagelos, sem envelope individual de mucilagem.

Distribuição na Bacia do Rio das Pedras: Ponto 18.

Características do riacho $(n=1)$ : temperatura $=16,5^{\circ} \mathrm{C}$; condutividade $=311 \mu \mathrm{S} \mathrm{cm}^{-1} ; \mathrm{pH}=7,5$; saturação de oxigênio $=78,5 \%$; turbidez $=2 \mathrm{NTU}$; velocidade da correnteza $=47,8 \mathrm{~cm} \mathrm{~s}^{-1}$.

Material examinado: BRASIL. PARANÁ: Guarapuava, Bacia do rio das Pedras, 21-VIII-2004, R.A. Krupek et al. s.n. (SJRP28252).

\section{Zygnema sp.}

Figura 36

Filamentos com células cilíndricas, 22,9-37,7 um compr., 24,6-26,2 um diâm. Zigósporos não observados.

Distribuição na Bacia do Rio das Pedras: Ponto 15.

Características do riacho $(\mathrm{n}=1)$ : temperatura $=12,6^{\circ} \mathrm{C}$; condutividade $=120 \mu \mathrm{S} \mathrm{cm}^{-1} ; \mathrm{pH}=7,1$; saturação de oxigênio $=77 \%$; turbidez $=3 \mathrm{NTU}$; velocidade da correnteza $=35,9 \mathrm{~cm} \mathrm{~s}^{-1}$.

Material examinado: BRASIL. PARANÁ: Guarapuava, Bacia do rio das Pedras, 28-VII-2004, R.A. Krupek et al. s.n. (SJRP28249).

Neste gênero as características das estruturas sexuadas (zigósporos) são indispensáveis para a identificação das espécies, sendo, por outro lado, as características vegetativas pouco importantes neste contexto. No material coletado nos riachos da Bacia do Rio das Pedras não foram encontradas populações férteis e por isso não foi possível a identificação em nível específico. 


\section{HETEROKONTOPHYTA}

\section{Vaucheria sp.}

Figura 37

Talo constituído por massa de filamentos formando emaranhados; filamentos cenocíticos amplamente ramificados. Anterídios e oogônios não observados.

Distribuição na Bacia do Rio das Pedras: Ponto 17.

Características do riacho $(\mathrm{n}=1)$ : temperatura $=18^{\circ} \mathrm{C}$; condutividade $=118 \mu \mathrm{S} \mathrm{cm}^{-1} ; \mathrm{pH}=7,1$; saturação de oxigênio $=69,5 \%$; turbidez $=11 \mathrm{NTU}$; velocidade da correnteza $=30,1 \mathrm{~cm} \mathrm{~s}^{-1}$.

Material examinado: BRASIL. PARANÁ: Guarapuava, Bacia do rio das Pedras, 21-VIII-2004, R.A. Krupek et al. s.n. (SJRP28251).

Nas populações analisadas não foram encontradas oogônios e anterídios, estruturas necessárias para a identificação específica.

\section{RHODOPHYTA}

\section{Batrachospermum puiggarianum Grunow in} Wittrock \& Nordstedt, Alg. Aq. Dulc. Exsic. 11: 1. 1883.

Figuras 38-39

Talo monóico, pouco mucilaginoso, ramificação irregular, abundante; verticilos reduzidos, obcônicos, separados 87,5-200 um diâm.; internó 205-460 um compr.; célula basal esférica, 2 ramos primários; córtex bem desenvolvido; ramos primários curvos 3-7 células; ramos secundários numerosos, curtos 1-3 células sobre até metade do internó; espermatângios esféricos ou obovóides, terminais ou subterminais; ramo carpogonial levemente arqueado, 1-3 células discóides sobre a célula basal ou proximais; filamentos bracteóides poucos, curtos, 1-2 células; carpogônio 1736 um compr.; tricogínio claviforme, indistintamente pedicelado; carposporófito central, 1-2 maior que

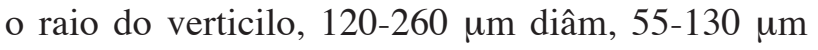
compr.

Distribuição na Bacia do Rio das Pedras: Pontos 09, $13,14,15,16,18$ e 19.

Características dos riachos $(\mathrm{n}=7)$ : temperatura $=$ $12,6-15,2^{\circ} \mathrm{C}(\overline{\mathrm{X}}=13,5)$; condutividade $=25,6-451 \mu \mathrm{S}$ $\mathrm{cm}^{-1}(\overline{\mathrm{X}}=207,5) ; \mathrm{pH}=6,8-7,7(\overline{\mathrm{X}}=7,2)$; saturação de oxigênio $=61 \%-91 \%(\bar{x}=75,4)$; turbidez $=1-21$ NTU $(\bar{x}=6)$; velocidade da correnteza $=34,3-74,0$ $\mathrm{cm} \mathrm{s}^{-1}(\overline{\mathrm{X}}=49,6)$.

Material examinado: BRASIL. PARANÁ: Guarapuava, Bacia do rio das Pedras, 28-VII-2004, R.A. Krupek et al. s.n. (SJRP28243); idem, 28-VII-2004, R.A. Krupek et al. s.n. (SJRP28247); idem, 28-VII-2004, R.A. Krupek et al. s.n. (SJRP28248); idem, 28-VII-2004, R.A. Krupek et al. s.n. (SJRP28249); idem, 28-VII2004, R.A. Krupek et al. s.n. (SJRP28250); idem, 21VIII-2004, R.A. Krupek et al. s.n. (SJRP28252); idem, 21-VIII-2004, R.A. Krupek et al. s.n. (SJRP28253).

Batrachospermum sirodotii Skuja ex Flint, Am. J. Bot. 37: 755. 1950.

Figuras 40-41

Talo monóico, moderadamente mucilaginoso; ramificação irregular abundante; verticilos esféricos, contíguos ou separados, 250-600 um diâm.; internó 200-650 um compr.; célula basal ovóide ou cilíndrica, 2-4 ramos primários; córtex bem desenvolvido; ramos primários 6-10 células; ramos secundários numerosos, retos ou levemente curvos, inclinados sobre todo o internó; espermatângios esféricos, terminais 5-7 $\mu \mathrm{m}$ diâm.; ramo carpogonial reto ou curvo; filamentos bracteóides poucos, curtos, 1-4 células; carpogônio 35-70 um compr.; tricogínio cilíndrico, pedicelado; carposporófito central, semi-esférico, menor que o raio do verticilo, 150-280 um diâm., 70-160 um compr.

Distribuição na Bacia do Rio das Pedras: pontos 14 e 16 .

Características dos riachos $(\mathrm{n}=2)$ : temperatura $=12,8$ $13,7^{\circ} \mathrm{C}$; condutividade $=147-267 \mu \mathrm{S} \mathrm{cm}^{-1} ; \mathrm{pH}=6,8-$ 7,2 ; saturação de oxigênio $=75 \%-81 \%$; turbidez $=1-3$ NTU; velocidade da correnteza $=34,3-51 \mathrm{~cm} \mathrm{~s}^{-1}$.

Material examinado: BRASIL. PARANÁ: Guarapuava, Bacia do rio das Pedras, 28-VII-2004, R.A. Krupek et al. s.n. (SJRP28248); idem, 28-VII-2004, R.A. Krupek et al. s.n. (SJRP28250).

Batrachospermum stagnale (Bory) Hassal, Hist. Brit. Freshw. Alg. 1845 三 Batrachospermum ludibundum var. stagnale Bory, Ann. Mus. Hist. Nat. 12: 325. 1808.

Figuras 42-43 

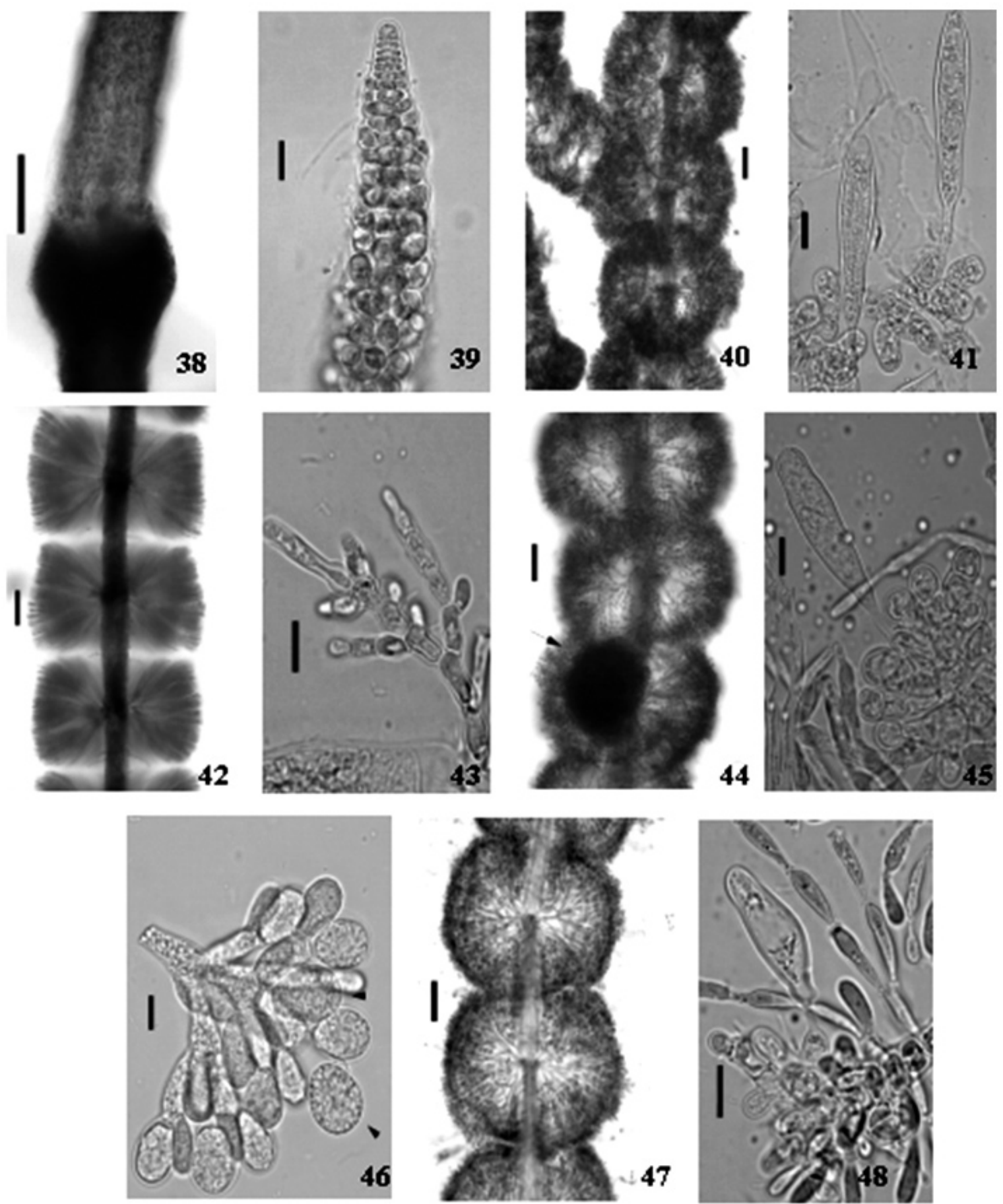

Figuras 38-48. Espécies de Rhodophyta da bacia do rio das Pedras. 38-39. Batrachospermum puiggarianum. 38. Vista geral de um verticilo. 39. Ápice de um filamento mostrando o arranjo compacto dos fascículos. 40-41. Batrachospermum sirodotii. 40. Vista geral dos verticilos. 41. Carpogônios maduros mostrando tricoginios. 42-43. Batrachospermum stagnale. 42. Vista geral dos verticilos. 43. Carpogônio maduro mostrando tricogínio. 44-46. Batrachospermum virgato-decaisneanun. 44. Vista geral dos verticilos com carposporofito (seta). 45. Carpogônio maduro mostrando tricogínio. 46. Filamentos gonimoblásticos com carposporângios (ponta de seta). 47-48. Batrachospermum vogesiacum. 47 . Vista geral dos verticilos. 48. Carpogônio maduro mostrando tricogínio. Barras de escala = 10 $\mu \mathrm{m}(39,41,43$, $45,46,48) ; 100 \mu \mathrm{m}(38,40,42,44,47)$. 
Talo dióico, moderado a abundantemente mucilaginoso; ramificação regular abundante; verticilos obcônicos, separados, 200-400 um diâm; interno 250-600 um compr.; célula basal ovóide, 2-4 ramos primários; córtex bem desenvolvido; ramos primários 6-12 células; ramos secundários numerosos, levemente curvos, inclinados sobre até metade do interno; espermatângios esféricos, terminais, 4-7 m diâm; ramo carpogonial reto; filamentos bracteóides poucos, longos, 2-6; carpogônio 40-75 m compr.; tricogínio cilíndrico, pedunculado; carposporófito central, menor que o raio do verticilo, 130-310 $\mu \mathrm{m}$ diâm., 90-180 بm compr.

Distribuição na Bacia do Rio das Pedras: Ponto 17.

Características do riacho $(n=1)$ : temperatura $=15,6^{\circ} \mathrm{C}$; condutividade $=240 \mu \mathrm{S} \mathrm{cm}^{-1} ; \mathrm{pH}=7,4$; saturação de oxigênio $=79 \%$; turbidez $=11 \mathrm{NTU}$; velocidade da correnteza $=39,4 \mathrm{~cm} \mathrm{~s}^{-1}$.

Material examinado: BRASIL. PARANÁ: Guarapuava, Bacia do rio das Pedras, 21-VIII-2004, R.A. Krupek et al. s.n. (SJRP28251).

\section{Batrachospermum virgato-decaisneanum Sirodot,}

Les Batrachospermes: 290. 1884.

Figuras 44-46

Talo dióico, moderadamente mucilaginoso; ramificação irregular abundante; verticilos esféricos ou doliformes, contíguos ou separados, 300-600 $\mu \mathrm{m}$ diâm; internó 300-600 $\mu \mathrm{m}$ compr.; célula basal ovóide ou cilíndrica, 2-4 ramos primários; córtex bem desenvolvido; ramos primários 4-10 células; ramos secundários numerosos, levemente curvos, inclinados sobre todo o interno; espermatângios esféricos, terminais, 4-8 $\mu \mathrm{m}$ diâm; ramo carpogonial levemente curvo; filamentos bracteóides poucos, longos, 2-4; carpogônio 30-60 um compr.; tricogínio cilíndrico, pedicelado; carposporófito central, esférico, 1-2 menor que o raio do verticilo, 120-280 um diâm., 70-160 um compr.

Distribuição na Bacia do Rio das Pedras: Ponto 9.

Características do riacho $(\mathrm{n}=1)$ : temperatura $=12,8^{\circ} \mathrm{C}$; condutividade $=409 \mu \mathrm{S} \mathrm{cm}^{-1} ; \mathrm{pH}=7,3$; saturação de oxigênio $=91 \%$; turbidez $=4 \mathrm{NTU}$; velocidade da correnteza $=74,0 \mathrm{~cm} \mathrm{~s}^{-1}$.
Material examinado: BRASIL. PARANÁ: Guarapuava, Bacia do rio das Pedras, 28-VII-2004, R.A. Krupek et al. s.n. (SJRP28243).

Batrachospermum vogesiacum Schultz ex Skuja, Arch. Hydrobiol. Suppl. 15: 623. 1938.

Figuras 47-48

Talo dióico, abundantemente mucilaginoso, ramificação irregular, abundante; verticilos obcônicos ou doliformes, contíguos, 450-800 um diâm.; internó 330-490 um compr.; célula basal ovóide ou cilíndrica; córtex pouco desenvolvido; ramos primários 7 -11 células; ramos secundários numerosos, poucos e esparsos, levemente curvos; espermatângios esféricos ou obovóides, terminais; ramo carpogonial reto, 1-4 células doliformes; filamentos bracteóides poucos, curtos, 1-3 células; carpogônio 60-74 um compr.; tricogínio claviforme, séssil; carposporófito central, nodal, semi-esférico, 1 (-2) vez menor que o raio do

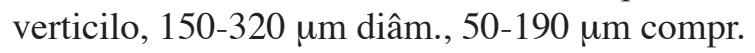

Distribuição na Bacia do Rio das Pedras: Ponto 17.

Características do riacho $(\mathrm{n}=1)$ : temperatura $=13,4$ ${ }^{\circ} \mathrm{C}$; condutividade $=202 \mu \mathrm{S} \mathrm{cm}^{-1} ; \mathrm{pH}=7,31$; saturação de oxigênio $=80,5 \%$; turbidez $=10$ NTU; velocidade da correnteza $=52,2 \mathrm{~cm} \mathrm{~s}^{-1}$.

Material examinado: BRASIL. PARANÁ: Guarapuava, Bacia do rio das Pedras, 21-VIII-2004, R.A. Krupek et al. s.n. (SJRP28251).

\section{Discussão}

Vinte e nove táxons subgenéricos e cinco grupos vegetativos (populações estéreis de Nitella, Oedogonium, Spirogyra, Zygnema e Vaucheria) foram encontrados em 19 segmentos de riachos examinados na Bacia do Rio das Pedras. Fischerella ambigua e Palmella mucosa são reportados pela primeira vez para o Brasil. Por outro lado, as espécies Phormidium autumnale, P. puteale, P. cf. schroederi, Stigonema robustum, Microspora quadrata, $M$. stagnorum, Tetraspora gelatinosa, Batrachospermum stagnale, B. virgato-decaisneanum e B. vogesiacum, são reportados pela primeira vez para o Estado do Paraná. Esta situação reflete claramente a carência de estudos taxonômicos e ecológicos envolvendo as comunidades de macroalgas de riachos brasileiros do Sul do Brasil e particularmente no Estado do Paraná. 
Várias espécies identificadas no presente estudo têm sido amplamente registradas como ocorrendo em ambientes lóticos de todo o mundo (p.ex., $B$. vogesiacum, B. sirodotii, Chaetophora elegans, M. quadrata, P. retzii, Stigeoclonium helveticum). Entretanto, de um modo geral, a flora das comunidades de macroalgas da Bacia do Rio das Pedras apresentouse relativamente diferente das encontradas em outras regiões brasileiras, com registro de espécies incomuns em estudos florísticos (p.ex., Ecballocystis pulvinata var. pulvinata, Komvophorom schimdlei, Nostoc verrucosum, $P$. autumnale, Tolypothrix byssoidea, P. тисова).

As divisões melhor representadas foram Cyanobacteria e Chlorophyta (cada uma com 14 táxons, $40 \%$ das espécies registradas), seguido de Rhodophyta (seis táxons, 17\%) e Heterokontophyta (um táxon, 3\%). O predomínio de representantes de Cyanobacteria e Chlorophyta, basicamente concorda com trabalhos anteriores, nos quais as duas divisões apresentam a grande maioria dos táxons inventariados em riachos no mundo todo (Sheath et al. 1989, $21 \%$ e 43\%; Entwisle 1990, $17 \%$ e 57\%; Sheath \& Cole 1992, 24\% e 35\%, respectivamente), incluindo regiões tropicais e subtropicais do Brasil (Necchi Júnior et al. 2000, 33\% e 41\%; Necchi Júnior et al. $2003,40 \%$ e $36,5 \%$, Peres et al. 2008, 58\% e $21 \%$ respectivamente). Phormidium retzii foi a espécie mais bem distribuída na Bacia do Rio das Pedras. Esta espécie tem sido reportada como sendo cosmopolita e de ampla distribuição em vários estudos. Sheath \& Cole (1992) em um estudo de 1.000 segmentos de riachos na América do Norte encontraram $P$. retzii como a mais bem distribuída espécie de macroalga. Necchi Júnior et al. (2000) também registraram esta espécie como predominante em levantamento realizado em 172 riachos do Estado de São Paulo.

A proporção de tipos morfológicos (segundo definição de Sheath \& Cole 1992) encontrada na área de estudo foi a seguinte: emaranhados (34\% dos táxons), filamento gelatinoso (20\%), colônia gelatinosa (17\%), filamentos livres (14\%), tufos $(10 \%)$ e incrustante (5\%). Tais resultados concordam, basicamente, com os apresentados em trabalhos anteriores (Branco \& Necchi Júnior 1996, 34\%, 12\%, 7,5\%, 22\%, 15\% e 7,5; Necchi Júnior et al. 1997, $31 \%, 6 \%, 10,5 \%, 40 \%, 12,5 \%$ e $0 \%$ respectivamente). Entretanto, algumas diferenças notáveis foram encontradas, particularmente com uma alta proporção de colônias e filamentos gelatinosos somada aos escassos registros de filamentos livres e tufos.
Talos gelatinosos, juntamente com o tipo filamentos emaranhados (tipo de talo predominante neste estudo) podem ser considerados como relativamente bem adaptados ao estresse mecânico provocado pela velocidade da correnteza (Sheath \& Hambrook 1990, Sheath \& Cole 1992). No presente estudo os valores médios de velocidade da correnteza foram elevados quando comparada a de estudos similares (Branco \& Necchi Júnior 1996, Necchi Júnior et al. 2000), assim, as proporções de tipos morfológicos aqui reportadas parecem ser absolutamente coerentes.

Os números totais de espécies, considerando o conjunto das amostragens (riqueza absoluta de espécies), foi relativamente alto, compatível com o reportado para estudos de outras regiões brasileiras (Necchi Júnior et al. 1994, Branco \& Necchi Júnior 1996, Necchi Júnior et al. 1997). Entretanto, a riqueza de espécies encontrada para os pontos de amostragem individualmente (riqueza relativa de espécies) revelou valores extremamente baixos, com grande parte das espécies sendo coletadas em apenas um único riacho (21 espécies ou $60 \%$ ). Esta forte presença de ocorrência restrita explicaria, de certa forma, a aparente contradição que foi observada entre um valor de riqueza absoluta de espécies relativamente alto na bacia como um todo e os baixos valores de riqueza relativa nos pontos individualmente. Estes resultados sugerem que as características próprias de cada ecossistema lótico determinam, em última análise, uma comunidade de macroalgas tipicamente local.

\section{Agradecimentos}

Os autores agradecem à Secretaria de Meio Ambiente e Desenvolvimento Florestal do Município de Guarapuava (PR) pela cessão do veículo utilizado nos trabalhos de campo e aos revisores anônimos pelos comentários altamente produtivos feitos na versão inicial que, seguramente, melhoraram a qualidade final do trabalho. $\mathrm{O}$ suporte financeiro para a execução deste trabalho foi oferecido pelo CNPq, através das bolsas de mestrado para RAK (130196/2004-5) e de produtividade em pesquisa para CCZB (520257/01-4).

\section{Literatura citada}

Anagnostidis, K. 1989. Geitlerinema, a new genus of oscillatorialean cyanophytes. Plant Systematics and Evolution 164: 33-46. 
Anagnostidis, K. \& Komárek, J. 1988. Modern approach to the classification system of cyanophytes. 3-Oscillatoriales. Algological Studies 50-53: 327472.

Anagnostidis, K. \& Komárek, J. 1990. Modern approach to the classification system of cyanophytes. 5-Stigonematales. Algological Studies 59: 1-73.

Battistelli, M. Camargo Filho, M. \& Heerdt, B. 2004. Proteção e Manejo da Bacia do Rio das Pedras - Relato de Experiências. Editora B \& D Ltda. Guarapuava.

Bittencourt-Oliveira, M.C., Massola Júnior, N.S., Hernandez-Marine, M., Romo, S. \& Moura, A.N. 2007. Taxonomic investigation using DNA fingerprinting in Geitlerinema species (Oscillatoriales, Cyanobacteria). Phycological Research 55: 214-221.

Branco, C.C.Z. \& Necchi Júnior, O. 1996. Survey of stream macroalgae of eastern Atlantic Rainforest of São Paulo State, southeastern Brazil. Archiv für Hydrobiologie 80: 35-57.

Branco, L.H.Z., Necchi Júnior, O. \& Branco, C.C.Z. 1999. Cyanophyceae from lotic ecosystems of São Paulo State, southeastern Brazil. Algological Studies 94: 63-87.

Branco, C.C.Z., Emed, R.G., Necchi Júnior, O. \& Branco, L.H.Z. 2008. Levantamento florístico das macroalgas de riachos da Floresta Nacional de Iratí, Estado do Paraná, Sul do Brasil. Acta Botanica Brasílica. No prelo.

Desikachary, T.V. 1959. Cyanophyta. Indian Council of Agricultural Research, New Dehli.

Drouet, F. 1937. The Brazilian Myxophyceae, I. American Journal of Botany 24: 598-608.

Entwisle, T.J. 1989. Macroalgae in Yarra River basin: flora and distribution. Proceedings of the Royal Society of Victoria 101: 1-76.

Entwisle, T.J. 1990. Macroalgae in the upper Yarra and Watts River catchments: Distribution and Phenology. Australian Journal of Marine and Freshwater Reserch 41: 505-22.

Filkin, N.R., Sherwood, A.R. \& Vis, M.L. 2003. Macroalgae from 23 stream in the Hawaiian Islands. Pacific Science 57: 421-31.

Fonseca, I.A. \& Rodrigues, L. 2005. Cianobactérias perifíticas em dois ambientes lênticos da planície de inundação do alto Rio Paraná. Revista Brasileira de Botânica 28: 821-834.

Holmgren, P.K. \& Holmgren, N.H. 1993. Additions to Index Herbariorum (Herbaria). Taxon 42: 489-505.

Komárek, J. \& Anagnostidis, K. 1986. Modern approach to the classification system of cyanophytes. 2-Chroococcales. Algological Studies 43: 157-226.
Komárek, J \& Anagnostidis, K. 1989. Modern approach to the classification system of cyanophytes. 4 . Nostocales. Algological Studies 56: 247-345.

Komárek, J. \& Anagnostidis, K. 2005. Cyanoprokaryota II. Teil Oscillatoriales. In: B. Büdel, L. Krienitz, G. Gärtner \& M. Schagerl (eds.). SüBwasserflora von Mitteleuropa 19. Elsevier Spektrum Akademischer Verlag, Munchen, pp. 1-759.

Komárek, J. \& Fott, B. 1983. Chlorophyceae (Grünalgen), Ordnung: Chlorococcales. In: G. Huber-Pestalozzi, H. Heynig \& D. Mollenhauer (eds.). Das Phytoplankton des Sübwassers. systematic und biologie. E. Schweizerbart'sche Verlagsbuchhandlung, Stuttgart, pp.1-1044.

Lee, R.E. 1989. Phycology. 2 ed. Cambridge University, Cambridge.

Maack, R. 2002. Geografia Física do Estado do Paraná. Imprensa Oficial, Curitiba.

Necchi Júnior, O., Dip, M.R. \& Goes, R.M. 1991. Macroalgae of a stream in southeastern Brazil: composition, seasonal variation and relation to physical and chemical variables. Hydrobiologia 213: 241-50.

Necchi Júnior, O., Pascoaloto, D. \& Branco, L.H.Z. 1994. Distribution of macroalgae in a tropical river basin from southeastern Brazil. Archiv für Hydrobiologie 129: 459-71.

Necchi Júnior, O., Branco, C.C.Z., Simões, R.C.G. \& Branco, L.H.Z. 1995. Distribution of stream macroalgae in northwest region of São Paulo State, southeastern Brazil. Hydrobiologia 299: 219-30.

Necchi Júnior, O., Pascoaloto, D., Branco, C.C.Z. \& Branco, L.H.Z. 1997. Stream macroalgal flora from the northwest region of São Paulo State, southeastern Brasil. Algological Studies 84: 91-112.

Necchi Júnior, O., Branco, C.C.Z. \& Branco, L.H.Z. 2000. Distribution of stream macroalgae in São Paulo State, southeastern Brazil. Algological Studies 97: 43-57.

Necchi Júnior, O., Branco, L.H.Z. \& Branco, C.C.Z. 2003. Ecological distribution of stream macroalgal communities from a drainage basin in the Serra da Cananstra National Park, Minas Gerais, southeastern Brazil. Revista Brasileira de Biologia 63: 635-46.

Peres, C.K., Branco, C.C.Z. \& Krupek, R.A. 2008. Macroalgas de riachos da Serra da Prata, leste do Paraná, sul do Brasil. Acta Botanica Brasilica. No prelo.

Romo, S., Miracle, R. \& Hernandez-Marine, M. 1993. Geitlerinema amphibium (Ag. ex Gom.) Anagnostidis (Cyanophyceae): morphology, ultraestructure and ecology. Algological Studies 69: 11-27. 
Sant'Anna, C.L. 1988. Scytonemataceae (Cyanophyceae) from the state of São Paulo, Southern Brazil. Nova Hedwigia 46: 519-539.

Sheath, R.G. \& Cole, K.M. 1992. Biogeography of stream macroalgae in North America Journal of Phycology 28: 448-460.

Sheath, R.G. \& Hambrook, J.A. 1990. Freshwater ecology. In: K.M. Cole \& R.G. Sheath (eds.). Biology of red algae. Cambridge University Press, Cambridge, pp. 423-453.

Sheath, R.G., Morinson, M.O., Korch, J.E., Kaczmarezyk, D. \& Cole, K.M. 1986. Distribuition of stream macroalgae in south-central Alasca. Hydrobiologia 135: 259-269.
Sheath, R.G., Hamilton, P.B., Hambrook, J.A. \& Cole, K.M. 1989. Stream macroalgae of eastern boreal forest region of North America. Canadian Journal of Botany 67: 3553-3562.

Southwood, T.R.E. 1978. Ecological methods, with particular reference to the study of insect populations. Chapman \& Hall, New York.

Van de Hoek, C., Mann, D.G. \& Jahns, H.M. 1995. Algae. An introduction to phycology. Cambridge University Press, Cambridge.

Whitton, B.A., Rott, E. \& Friedrich, G. 1991. Use of algae for monitoring rivers. Institute of Botany, University of Innsbruck, Innsbruck. 